\title{
EVIDENCE FOR THE EXISTENCE OF THE MEDIEVAL WARM PERIOD IN CHINA
}

\author{
ZHANG DE'ER
}

Chinese Academy of Meteorological Sciences, Baishiqiaolu No. 46 Beijing 100081, China

\begin{abstract}
The collected documentary records of the cultivation of citrus trees and Boehmeria nivea (a perennial herb) have been used to produce distribution maps of these plants for the eighth, twelfth and thirteenth centuries A.D. The northern boundary of citrus and Boehmeria nivea cultivation in the thirteenth century lay to the north of the modern distribution. During the last 1000 years, the thirteenthcentury boundary was the northernmost. This indicates that this was the warmest time in that period. On the basis of knowledge of the climatic conditions required for planting these species, it can be estimated that the annual mean temperature in south Henan Province in the thirteenth century was $0.9-1.0^{\circ} \mathrm{C}$ higher than at present. A new set of data for the latest snowfall date in Hangzhou from A.D. 1131 to 1264 indicates that this cannot be considered a cold period, as previously believed.
\end{abstract}

\section{Introduction}

Since the thermal optimum of the Holocene, the general trend of temperature in China has been a decline with secondary fluctuations of cooling and warming. The cooling stage, namely the Little Ice Age, has been discussed in more detail elsewhere (Grove, 1988; Zhang, 1991, 1992), as have the warming stages in the Han Dynasty (second century B.C.) and the Tang Dynasty (seventh to ninth centuries) (Chu, 1973). As for the Medieval Warm Period, nominally assigned to A.D. 900 to 1300 , its existence in China has also been established by reference to contemporary documents.

There exist numerous records of the cultivation of citrus trees and the harvest of Boehmeria nivea (a perennial herb) in old Chinese documents. These records reflect the changes in where they were planted at different times. Both citrus and Boehmeria nivea are subtropical plants, whose growth and yield depend so closely on thermal conditions that we can adopt their planting boundary as a good indicator of temperature variations. We may also consider the period in which they were grown furthest north as the warmest period. Knowledge of modern climate limitations of their successful cultivation and harvest can be used to infer historical climatic conditions as their northern boundary. Chu $(1931,1973)$ considered the period around A.D. 1200 to be cold. This conclusion was in part based on a set of data on snowfall dates in Hangzhou in the South Song Dynasty. Recently the author's work based on a recalculation of the calendar conversion from the original lunar calendar to a solar calendar for ancient original records, revealed that almost all of the recalculated dates are earlier than thought hitherto. Consequently, the previous conclusion should be revised. This issue will be discussed further below. 


\section{Information Obtained from Ancient Records of Planting Boehmeria nivea}

\subsection{The Historical Planting Distribution}

Boehmeria nivea is a tropical-subtropical perennial herb and has been used as a raw material for clothing since ancient times. It is very sensitive to temperature variation and would yield two to five crops a year depending on the thermal conditions. Chinese historical documents contain detailed descriptions of the planting and harvesting of this herb. In this paper, only descriptions extracted from the official documents of the Tang Dynasty (A.D. 618-907), the North Song Dynasty (A.D. 960-1127) and the Mongol-Yuan Dynasty (A.D. 1206-1368) are used to map planting of Boehmeria nivea (Figure 1).

For the eighth century, a total of 130 planting places, now located in 101 counties (Tan, 1982) were found in the 'New Tang Dynasty Book' (Ou Y.X., 1061). In the 'Song Dynasty History', 133 planting places, now located in 101 counties, are noted (Tan, 1982). These are shown for the years A.D. 1102-1105. For the Yuan Dynasty, the relevant records are obtained exclusively from an official agriculture direction book 'Nong Sang Ji Yao', compiled by 'Da Si Nong Si' (ministry of agriculture) on orders from the emperor to direct agricultural production for the whole country in A.D. 1264 and issued by government in A.D. 1273. In this book there are descriptions such as:

"the Boehmeria nivea planted in Southern China previously can be planted in Henan province now (A.D. 1264)"

"at present (A.D. 1264), around Chen county and Cai country... there can be three crops a year. . the yield is $30 \operatorname{Jin}$ (a weight unit equal to $0.5 \mathrm{~kg}$ ) per $M u$ (a unit of area, equal to $0.0667 \mathrm{ha}$ ) and the price is $300 \mathrm{Wen}$ (A monetary unit) per Jin" (Wang Pan, 1273)

This means that Chen county (i.e. Huiyang today) and Cai county (i.e. Runan today) were the northernmost boundary of Boehmeria nivea, and three crops a year were obtained there in the mid-thirteenth century. It is noteworthy that the Boehmeria nivea had become a new local production in these places in the mid-thirteenth century. This fact reflects that the warm, stable climate favored this production. Comparing these planting distributions for different dynasties, it can be seen that, during the Yuan Dynasty, the northern boundary lay to the north of that which existed during the Tang and the Song dynasties, and much further north than today (Figure 1).

\subsection{Inference of Temperature at the Northern Boundary of Boehmeria nivea in the Thirteenth Century}

The growth and harvest of Boehmeria nivea require certain temperature conditions. In general, this plant requires an accumulated temperature of $1400-1700^{\circ} \mathrm{C}$ greater 

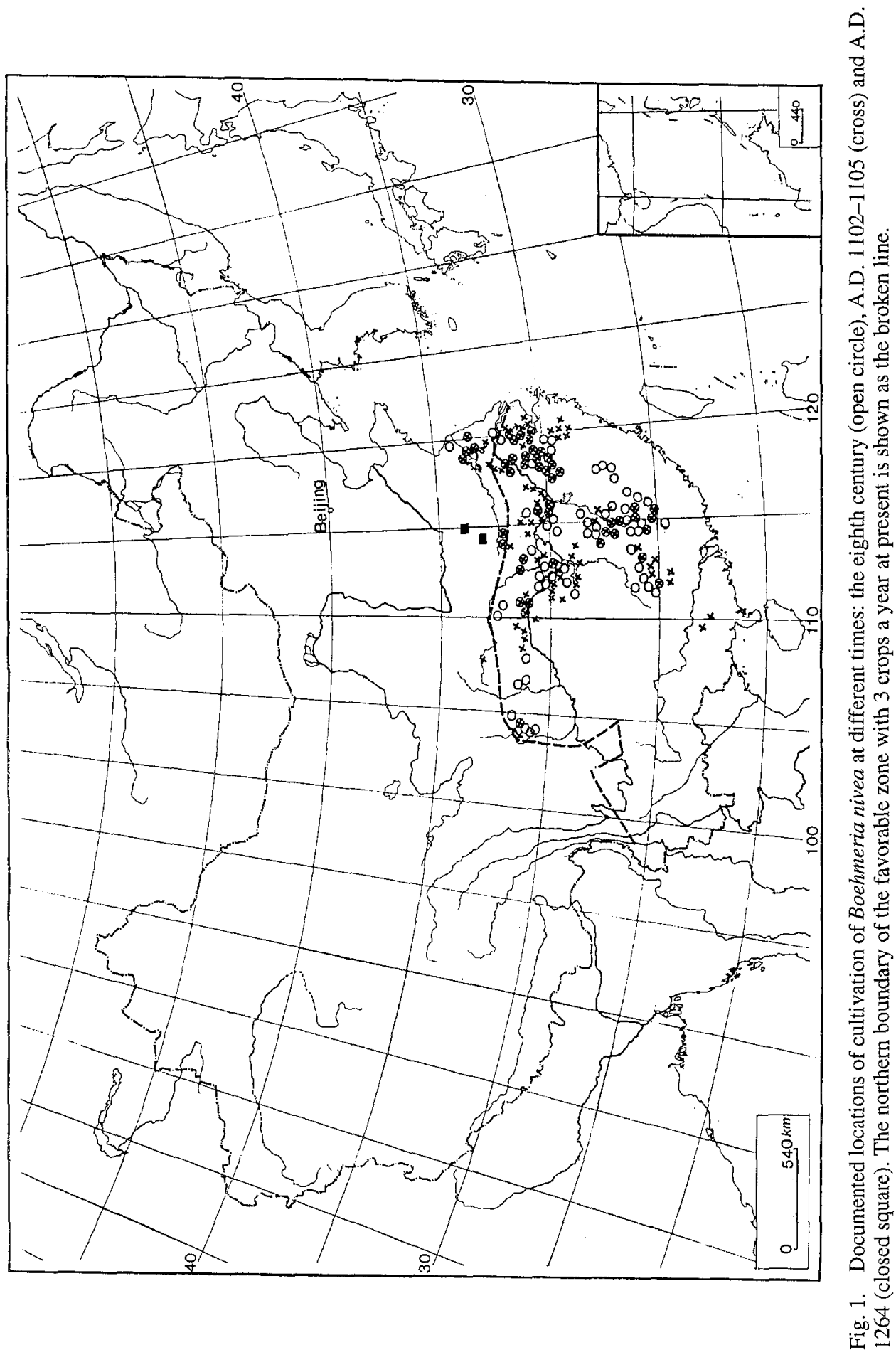
than $10^{\circ} \mathrm{C}$. The temperature range favorable to growth is $9-35^{\circ} \mathrm{C}$ (Han, 1991). It has two crops a year in the temperate zone and five crops a year in regions with warmer, wetter conditions. The climatic regionalization of Boehmeria nivea is divided into four zones: the most, favorable zone, subfavorable zone and unfavorable planting zone (Cheng, 1991). Boehmeria nivea can yield three crops a year only in the favorable zone, where the annual temperature is about $15.5-16.5^{\circ} \mathrm{C}$, mean monthly temperature in January is $1.5-3{ }^{\circ} \mathrm{C}$ and the soil minimum temperature at $5 \mathrm{~cm}$ depth in January is $3.2-4.5^{\circ} \mathrm{C}$ (from agroclimatic data stored in the Chinese Academy of Meteorological Sciences). In the thirteenth century, the northernmost places with three crops a year were located in Huiyang and Runan. Based on meteorological records (1961-1980), the annual mean temperature at Huiyang and Runan are $14.5^{\circ} \mathrm{C}$ and $15.1^{\circ} \mathrm{C}$, mean January temperatures are $0.9^{\circ} \mathrm{C}$ and $1.2^{\circ} \mathrm{C}$ and extreme minimum temperatures are $-12.3^{\circ} \mathrm{C}$ and $-10.0^{\circ} \mathrm{C}$ respectively. It is warmer at Runan than Huiyang. Thus, we can infer the temperatures at Huiyang in the thirteenth century by the lower limit of temperatures $\left(15.5^{\circ} \mathrm{C}, 1.5^{\circ} \mathrm{C}\right)$ of the favorable planting zone of Boehmeria nivea, and the inferred temperatures at Runan should be greater than the lower limit value. Table I shows the inferred temperature values at Huiyang and Runan, the northernmost places with three crops a year in the thirteenth century. This indicates that annual temperatures in the thirteenth century are nearly $1{ }^{\circ} \mathrm{C}$ higher than at present, and that the monthly mean temperature in January was about $0.6^{\circ} \mathrm{C}$ higher.

TABLE I: Comparison between the temperature value $\left({ }^{\circ} \mathrm{C}\right)$ inferred in the thirteenth century $(\mathrm{A})$ and that measured at present (B)

\begin{tabular}{|c|c|c|c|c|c|c|c|c|c|}
\hline \multirow[b]{2}{*}{ Place } & \multicolumn{3}{|c|}{ Annual Temp. } & \multicolumn{3}{|c|}{ January temp. } & \multicolumn{3}{|c|}{ Extr. Min. Temp. } \\
\hline & $\bar{A}$ & $\bar{B}$ & $\overline{A-B}$ & $\mathrm{~A}$ & $\mathrm{~B}$ & $\overline{\mathrm{A}-\mathrm{B}}$ & $\bar{A}$ & B & $\overline{A-B}$ \\
\hline Hui Yang & 15.5 & 14.5 & 1.0 & 1.5 & 0.9 & 0.6 & - & -12.3 & - \\
\hline Ru Nan & $>15.5$ & 15.1 & - & $>1.5$ & 1.2 & - & - & -10.0 & - \\
\hline Den Xian & $>16.0$ & 15.3 & - & $>2.0$ & 1.7 & - & $>7.0$ & -9.8 & - \\
\hline Tang He & 16.0 & 15.1 & 0.9 & 2.0 & 1.4 & 0.6 & -7.0 & -10.5 & 3.5 \\
\hline
\end{tabular}

\section{Information Obtained from Ancient Records of Planting Citrus}

\subsection{The Historical Planting Distribution of Citrus}

Citrus trees prefer a warm and moist climate, and have a long history of cultivation in China. From the 'New Tang Dynasty Book' (Ou Y. X., 1061), we have collected the records of 145 locations where cultivated citrus trees grew. These locations today span 91 counties (Figure 2) and show the actual distribution of citrus in the eighth century. As for the Yuan Dynasty, a significant record was obtained from the official agriculture direction book 'Non Sang Ji Yao', viz.: - 


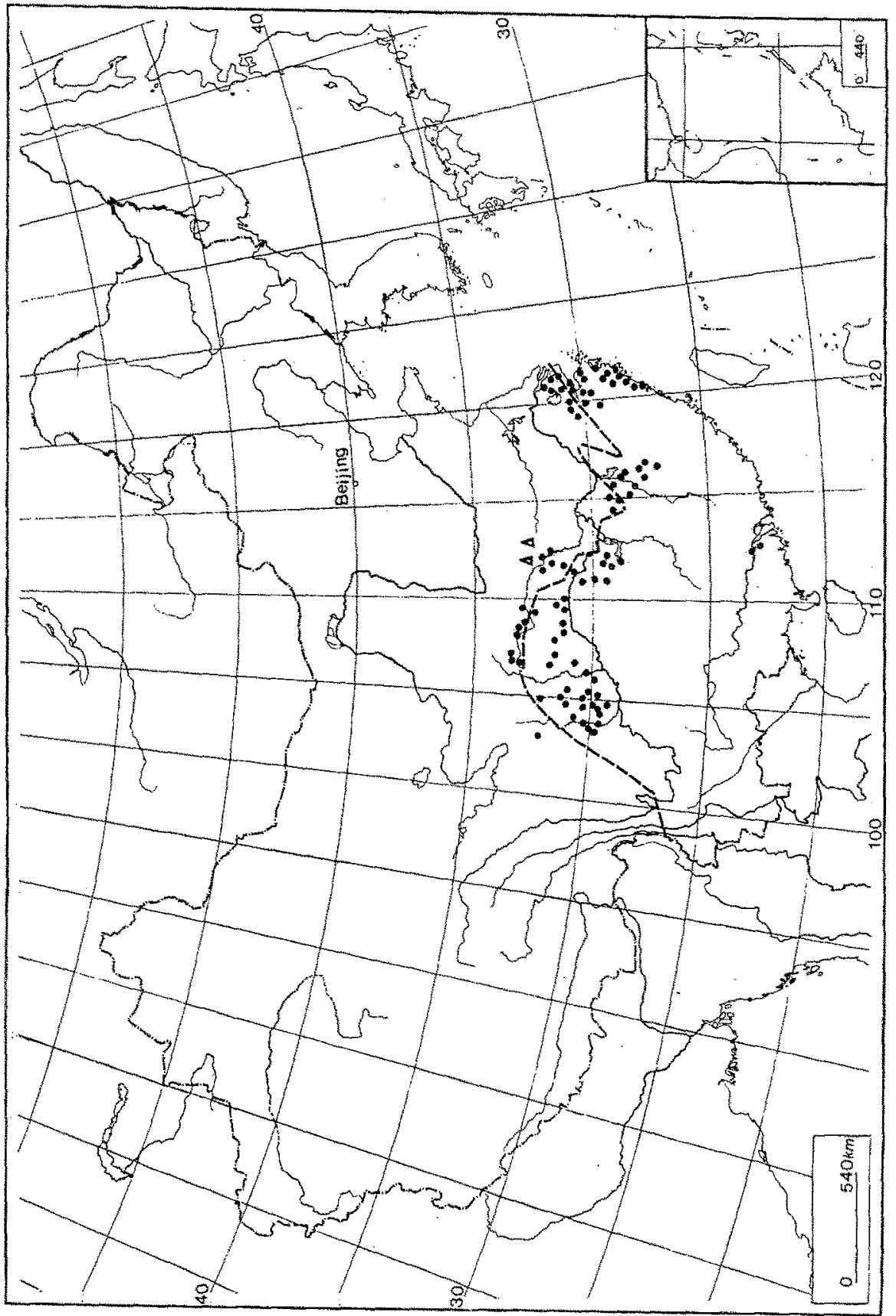

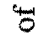

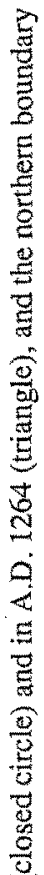

를

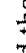

急

要:

홍 焉 范 $\stackrel{8}{5}$ 这 泣. 9 管 을 焉 5 열 $8 \geqslant$ 궁 这 
"Orange is a new crop found in Xichuan, Tang county and Deng county. Citrus has been cultivated successfully in these places recently (A.D. 1264)" (Wang Pan, 1273)

This record reflects actual cultivation in the period around A.D. 1264. These places (i.e. Tanghe county and Deng county today) can be considered as the northernmost county of citrus cultivation at that time (Figure 2). It can be shown that the northern boundary of citrus cultivation in the mid-thirteenth century was north of that in the Tang Dynasty and even further north than the present limit (He Kang, 1985).

\subsection{Inference of Temperature on the Northern Boundary of Citrus Trees in the Thirteenth Century}

The cultivation of citrus trees is sensitive to thermal conditions, especially to the minimum. In general, it is considered necessary for successful citrus cultivation that the minimum temperature be above $-5^{\circ} \mathrm{C}$. The study of climatic regionalization of citrus (Chinese Academy of Agriculture Science, 1980) based on present climatic data results in the designation of five cultivating zones with defined temperature indicators. The subfavorable cultivation zone is defined by annual mean temperatures over $16^{\circ} \mathrm{C}$, monthly mean temperatures $2-5^{\circ} \mathrm{C}$ and mean extreme minimum temperatures greater than $-7^{\circ} \mathrm{C}$. It is noteworthy that the recent northern boundary of the subfavorable zone (indicated in Figure 2 by the broken line) almost coincides with the present main citrus-producing area. According to such climatic indicators, we can consider temperature conditions on the northern boundary of the subfavorable zone as being: annual mean temperature is $16^{\circ} \mathrm{C}$, monthly mean temperature in January is $2{ }^{\circ} \mathrm{C}$ and mean extreme minimum temperature is $-7^{\circ} \mathrm{C}$. Therefore, supposing the temperature conditions of the northernmost citrus cultivation in the thirteenth century to be analogous to those of the northern boundary of the subfavorable zone today, the temperature of Tanghe county and Deng county in the mid-thirteenth can be inferred as shown in Table I. The indications are that the annual mean temperature in the mid-thirteenth century was $0.9^{\circ} \mathrm{C}$ higher, the monthly mean January temperature was $0.6^{\circ} \mathrm{C}$ higher, and the mean extreme minimum temperature was probably $3.5^{\circ} \mathrm{C}$ higher than at present.

\section{New Data on the Spring Snowfall Date in Hangzhou During the South Song Time (A.D. 1131-1264)}

Records of spring snowfall dating from A.D. 1131 to 1264 in Hangzhou, the capital of the South Song Dynasty, have hitherto been used to define this as a period of cold conditions (Chu, 1973). Recently, we have obtained more records from other historical documents (shown in Table II and marked by $*, * *$ ). We checked all of these original records and re-examined their calendar conversion from the lunar calendar to the solar calendar using new conversion books (Chen, 1962; Fang, 1987). We found that almost all the revised dates of spring snowfall are earlier 
TABLE II: The latest date of spring snowfall in Hangzhou (A.D. 1131-1264)

\begin{tabular}{|c|c|c|c|}
\hline Year & $\begin{array}{l}\text { Date } \\
\text { (revised) }\end{array}$ & $\begin{array}{l}\text { Date } \\
\text { (previous) }\end{array}$ & $\begin{array}{l}\text { Difference } \\
\text { (day) }\end{array}$ \\
\hline 1131 & Apr. 4 & Apr. 11 & +7 \\
\hline 1135 & Mar. 16 & Mar. 24 & +7 \\
\hline 1136 & Mar. 8 & Mar. 15 & +7 \\
\hline 1143 & Apr. 12 & Apr. 19 & +7 \\
\hline 1147 & Mar. 5 & Mar. 12 & +7 \\
\hline 1148 & Mar. 6 & Mar. 13 & +7 \\
\hline 1158 & Apr. 6 & Apr. 13 & +7 \\
\hline 1159 & Mar. 4 & Mar. 11 & +7 \\
\hline 1161 & Feb. 22 & Feb. 26 & +4 \\
\hline 1164 & Mar. 16 & Mar. 23 & +7 \\
\hline 1165 & Mar. 30* & & \\
\hline 1166 & Mar. 25 & Apr. 1 & +7 \\
\hline 1167 & Mar. $6^{* *}$ & & \\
\hline 1168 & Apr. 2 & Apr. 12 & +10 \\
\hline 1169 & Mar. 1 & Mar. 8 & +7 \\
\hline 1171 & Mar. 19 & Mar. 26 & +7 \\
\hline 1186 & Mar. $8 * *$ & & \\
\hline 1188 & Mar. $20^{* *}$ & & \\
\hline 1189 & Mar. 1* & & \\
\hline 1190 & Mar. 19 & Mar. 19 & 0 \\
\hline 1191 & Feb. 26 & Mar. 15 & +17 \\
\hline 1193 & Mar. 26 & Apr 2 & +7 \\
\hline 1197 & Mar. $10^{*}$ & & \\
\hline 1199 & Mar. 6 & Mar. 13 & +7 \\
\hline 1200 & Mar. 15 & Mar. 22 & +7 \\
\hline 1204 & Mar. 1** & & \\
\hline 1207 & Mar. 2 & Mar. 9 & +7 \\
\hline 1208 & Mar. 2 & Mar. 9 & +7 \\
\hline 1211 & Mar. 9 & Mar. 16 & +7 \\
\hline 1213 & Mar. 9 & Mar. 18 & +9 \\
\hline 1216 & Mar. 2 & Mar. 9 & +7 \\
\hline 1217 & Mar. 23 & Mar. 30 & +7 \\
\hline 1223 & Apr. $12 *$ & & \\
\hline 1224 & Apr. 6 & Mar. 14 & -23 \\
\hline 1225 & May $9 * *$ & & \\
\hline 1230 & Mar. $6^{* *}$ & & \\
\hline 1231 & Mar. 17 & Mar. 24 & +7 \\
\hline 1233 & Apr. 18 & May 16 & +28 \\
\hline 1234 & Mar. 5 & Mar. 12 & +7 \\
\hline 1235 & Mar. 22 & Mar. 29 & +7 \\
\hline 1238 & Mar. 6* & & \\
\hline 1246 & Mar. 1 & Mar. 8 & +7 \\
\hline 1253 & Mar. 4 & Mar. 11 & +7 \\
\hline 1254 & Apr. 4 & Apr. 11 & +7 \\
\hline 1259 & Mar. 1 & Mar. 8 & +7 \\
\hline 1264 & Mar. 5 & Mar. 12 & +7 \\
\hline
\end{tabular}


in the year than those used previously. This revised result is very significant for the re-evaluation of the previous conclusion which indicated that a cold period occurred around A.D. 1200 (Chu, 1925, 1973). The previous conclusion is based on statistics of the latest snowfall date for both of the South Song period and the present. It was pointed out that "the average date of latest snowfall for each decade during the South Song time was April 9, almost a month later than the date of the latest spring snowfall for a decade in the first half of the twentieth century", and "Hangzhou was $1-2{ }^{\circ} \mathrm{C}$ colder in terms of the monthly mean temperature for April during the South Song time" (Chu, 1973). The re-examination of this record resulting from the revised calendar conversion indicates that the renewed date is, on average, eight days earlier than previously thought, and the earliest case is moved by 28 days. According to the revised data, the average date of the latest snowfall for each decade during the South Song time was 27 March, not April 9. Thus, the previous conclusion about estimated temperature for April in the South Song time should be revised. At least, the South Song time (around A.D. 1200) can not be considered as one of the coldest periods in the last 5000 years in China, as previously indicated. In this way, a contradiction with the nominal time interval of the Medieval Warm Period (A.D. 900-1300) may be partly resolved.

\section{Conclusions}

During the last 1300 years, the northern boundary of the cultivation of citrus trees and Boehmeria nivea has moved. The northernmost extent of cultivation of both plants occurred in the thirteenth century. As both plants are subtropical and sensitive to variations in thermal conditions, the thirteenth century can be considered as the warmest interval in this period. Temperature conditions in central China during the thirteenth century can be inferred on the basis of current climatic regionalization for citrus and Boehmeria nivea, and the thirteenth century locations of citrus crops and places where Boehmeria nivea yielded three crops per year. It is suggested that annual mean temperatures in the thirteenth century were $0.9-1.0^{\circ} \mathrm{C}$ higher than present, monthly mean temperatures in January, and mean extreme minimum temperatures were $0.6^{\circ} \mathrm{C}$ and $3.5^{\circ} \mathrm{C}$ higher than present respectively. On the basis of the revised data for spring snowfall dates in Hangzhou (A.D. 1131-1264) it is pointed out that the previous conclusion that the South Song time was one of the coldest in recent millennia should be revised.

\section{Acknowledgements}

This research is supported by the National Science Foundation of China. I am indebted to Dr. Malcolm K. Hughes for his kind help in revising the manuscript in English. Thanks are also due to Dr. Marjorie G. Winkler for her help in preparing this paper. 


\section{References}

Cheng Chunsu: 1991, Climate and Agriculture in China, Meteorology Press, Beijing, p. 275, (in Chinese).

Chen Yuan: 1962, The Table of Intercalary Months and Date in the Twenty Histories, Zhong-Hua Publishing House, Beijing, pp. 138-150.

Chinese Academy of Agriculture Science: 1980, "A Study on Climatic Regionalization of Citrus in China', Agrometeorol. J. 2, 13-18, (in Chinese).

Chu C. C.: 1925, Collected Papers of Dr. Zhu K. Z., Science Press, Beijing, p. 53, (in Chinese).

Chu Co-Ching: 1931, 'Climatic Changes during Historical Times in China', Gerlands Beitrage zur Geophysik, Koppen, Band 1, 33, 29-27, Leipzig.

Chu Co-Chen: 1973, 'A Preliminary Study on the Climatic Fluctuations during the Last 5000 Years in China', Sci. Sinica 14, 226, 236, 237.

Fang Shimin: 1987, Conversion Table of the Chinese Historical Calendar, Ci-Shu Publishing House, Shanghai, (in Chinese).

Grove, J.: 1988, The Little Ice Age, Methuen, London and New York.

Han Xiangling: 1991, Crop Ecology, Meteorology Press, Beijing, pp. 199-205.

He Kang: 1985, National Atlas of Agriculture in China, Photography Publishing House, Beijing, p. 114.

Ou Yangxiu: 1061, New Tang Dynasty Book, Section on geography, pp. 35-40 (in Chinese).

Tan qixiang: 1982, The Historical Atlas of China, Photography Publishing House, Beijing, pp. 5-7.

Tuo Tuo: 1343, History of the Song Dynasty, Section on geography 85-90, section on five elements 167-184 (in Chinese).

Xu Song: (Nineteenth Century), Song Hui Yao Ji Gao, Zhong- Hua Publishing House, Beijing, pp. 2089-2090, (in Chinese).

Wang Pan: 1273, Nong Sang Ji Yao, (Thread-bound Chinese book).

Zhang De'er: 1991, 'The Little Ice Age in China and Its Correlations with Global Change', Quatern. Sci. 3, 104-106, (in Chinese).

Zhang De'er: 1992, 'The Little Ice Age in China', CODATA Bull. 4, 91-100. 